\title{
Access to therapy and therapy outcomes in the Swiss Hepatitis C Cohort Study: a person-centred approach
}

Running title: Socio-behavioural hepatitis C subgroups

Fabio Giudici*1, Barbara Bertisch*1,2, Francesco Negro ${ }^{3}$, Guido Stirnimann ${ }^{4}$, Beat Müllhaupt ${ }^{5}$, Darius Moradpour ${ }^{6}$, Andreas Cerny ${ }^{7}$, Olivia Keiser ${ }^{1}$ for the Swiss Hepatitis C Cohort Study ${ }^{\ddagger}$

* equal contribution

1) Institute of Social and Preventive Medicine, Bern, Switzerland

2) Checkpoint Zürich, Zürich, Switzerland

3) Divisions of Gastroenterology and Hepatology and of Clinical Pathology, University Hospitals, Geneva, Switzerland

4) University Clinic of Visceral Surgery and Medicine, Inselspital, Bern, Switzerland

5) Swiss Hepato-Pancreato-Biliary Center and Department of Gastroenterology and Hepatology, University Hospital, Zürich, Switzerland

6) Division of Gastroenterology and Hepatology, University Hospital, Lausanne, Switzerland

7) Epatocentro Ticino SA, Lugano, Switzerland

Correspondence:

Olivia Keiser

University of Bern

Institute of Social and Preventive Medicine

Finkenhubelweg 11, 3012 Bern

Email: olivia.keiser@ispm.unibe.ch

Phone: +41316313515

$¥$ The Swiss Hepatitis C Cohort Study group comprises Francesco Negro, Laurent Kaiser (Geneva); Markus Heim, Hans Hirsch (Basel); Jean-François Dufour, Meri Gorgievski (Bern); Darius Moradpour, Vincent Aubert (Lausanne); Hans H. Siegrist (La Chaux-de-Fonds); Andreas Cerny, Gladys Martinetti Lucchini (Lugano); Raffaele Malinverni (Neuchâtel); David Semela, Patrick Schmid, Günter Dollenmaier (St. Gallen); Beat Müllhaupt, Elsbeth Probst-Müller (Zürich); Thomas Fabbro, Marielle Rudquist, Pascal Benkert (Basel Clinical Trial Unit). 


\section{Abstract}

Background: Socio-demographic and behavioural characteristics are associated with delayed diagnosis and disease progression in HCV-infected persons. However, many analyses focused on single variables rather than groups defined by several variables.

Methods: We used latent class analysis to study all 4,488 persons enrolled in the Swiss Hepatitis C Cohort Study. Groups were identified using pre-defined variables at enrolment. The number of groups was selected using the Bayesian Information Criterion. Mortality, loss to follow-up, cirrhosis, treatment status and response to antivirals were analysed using Laplace and logistic regressions.

Results: We identified five groups and named them according to their characteristics: persons who inject drugs, male drinkers, Swiss employees, foreign employees and retirees. Two groups did not conform to common assumptions about persons with chronic hepatitis $C$ and were already in an advanced stage of the disease at enrolment: "male drinkers" and "retirees" had a high proportion of cirrhosis at enrolment ( $15 \%$ and $16 \%$ vs $<10.3 \%$ ), and the shortest time to death (adjusted median time 8.7 years and 8.8 years vs >9.0). "Male drinkers" also had high substance use, but they were well educated and were likely to be employed.

Conclusions: This analysis may help identifying high risk groups which may benefit from targeted interventions.

Key words: alcohol, hepatitis C, latent class analysis, persons who inject drugs, socio-behaviour, Switzerland 


\section{Introduction}

Hepatitis C virus (HCV) infection is one of the major causes of chronic hepatitis, cirrhosis and hepatocellular carcinoma. HCV-associated complications are increasingly prevalent in Switzerland and other countries [1-5]. New options to treat HCV with direct-acting antivirals (DAA) can reach sustained virologic response rates (SVR) between $85 \%$ and $100 \%$ [5-7]. These new treatments will decrease the long-term risk of liver disease complications, but more than $50 \%$ of HCV cases are still undiagnosed in Switzerland $[1,2,8]$ and elsewhere $[1,7,9]$. To reap the full benefit of the new HCV therapies, testing coverage must increase, and testing must be linked to care.

Socio-demographic and behavioural characteristics are associated with delayed diagnosis or treatment, [10-12] as well as adherence to treatment [10,11]. Among other factors, studies have associated age [13], gender [14], and alcohol consumption [15] with access to therapy, but they have usually focused on single variables. The combined effect of several characteristics could be evaluated with a person-centred approach, which would begin by grouping persons with similar characteristics and then determining the associations between these groups and specific outcomes.

Clinicians must make many decisions when they interact with persons, decide on appropriate treatments, and adapt treatments to persons. The practice of diagnostic reasoning is central to daily patient management, especially in personalized health care settings [16]. For example, clinicians may decide to test a patient for HCV if they suspect intravenous drug use. Similarly, when clinicians decide whether to treat a patient or not, they will consider both biomedical aspects and the context in which treatment is prescribed, including a patient's tolerance for medication, lifestyle and anticipated adherence to therapy [16]. Clinicians often categorize persons, based on both clinical observation and their perception of the patient's personal characteristics [17]. Diagnostic reasoning is a complex process, and it can be supported by latent class analysis (LCA) [18], a multivariate statistical analysis technique that can identify distinct subgroups (latent classes) that cannot be observed directly, but are inferred from available data [18]. In LCA, heterogeneity within the classes is low, and the variables that define classes are independent. We used LCA in the Swiss Hepatitis C Cohort Study (SCCS) to: (1) define different socio-demographic and behavioural groups; (2) describe the characteristics of these groups; (3) determine if belonging to these

groups is associated with access to care and clinically relevant outcomes (for example, high risk of loss-tofollow-up, developing cirrhosis, or poor treatment response). 


\section{Materials and methods}

\section{Swiss Hepatitis C Cohort Study (SCCS)}

The SCCS, established in 2000, includes persons aged $\geq 18$ years with positive anti-HCV antibodies [19]. Participants are enrolled at eight centres, including five university teaching hospitals (Basel, Bern, Geneva, Lausanne and Zurich), two regional hospitals (Neuchatel and St. Gallen) and a regional hepatology centre (Lugano) [19]. Data are collected by standardized questionnaires, which are completed during clinical visits at enrolment and annual follow-up. Data comprise socio-demographic and behavioural information, including gender, date of birth, nationality, the occupational situation, education, risk factors for HCV infection, and drug and alcohol consumption. There is also data from clinical evaluations: anthropometric measures and assessments of liver cirrhosis; laboratory tests, including assays for liver function, HCV viral load and genotype, serological markers of hepatitis B virus (HBV) and human immunodeficiency virus (HIV) infections; and Fibroscan ${ }^{\circledR}$ and/or liver histology results. Data quality is checked periodically by the Clinical Trial Unit at the University Hospital Basel. Ethical approval for data collection was obtained from the ethics committees of the eight participating centres. All subjects gave informed consent.

\section{Eligibility criteria and definitions}

The study included all patients enrolled as of December $31^{\text {st }}, 2014$. We categorized the following variables for the LCA: age ( $\leq 40,41-59, \geq 60$ years), nationality (Swiss, foreign), and occupational status (working or studying, unemployed, retired or social assistance). Additionally, we defined participants as persons who inject drugs (PWID) if previous or ongoing injecting drug use was mentioned in the questionnaire (in a sensitivity analysis we considered three groups: no, current, former drug use); and as no or light drinkers of alcohol ( $\leq 20 \mathrm{~g}$ alcohol/day), moderate to heavy drinkers (>20 g alcohol/day), or former moderate to heavy drinkers (used to drink >20 g alcohol/day before, but currently stopped). Education (low, medium, high) was classified according to the definitions provided by the Swiss Conference of Cantonal Ministers of Education [20]. We grouped HCV genotypes into categories 1 to 4 (genotypes 5 and 6 were set to missing since only 11 persons had these genotypes). Since in most cases the date of HCV infection was unknown or uncertain, we used the date of the first positive anti-HCV test as a proxy and classified the persons into four groups ( $\leq 1,2-5,6-10,>10$ years from date of first positive test to date of enrolment). 


\section{Latent Class Analysis}

We used LCA to define groups of persons whose socio-demographic and behavioural characteristics were similar at enrolment into the cohort. We chose and categorized variables before we began the analysis. The following variables defined the groups: gender, age, education, occupational situation, nationality, drug use, and alcohol consumption. We conducted the analysis in steps, beginning with one class and then increasing the number of classes by one. We used the Bayesian Information Criterion (BIC) to define the optimal number of classes [21]. Based on their socio-demographic and behavioural characteristics, persons were assigned to groups they were most likely to belong to. We used Mplus software (Muthen \& Muthen, Los Angeles, CA, USA, 2009) for the LCA.

\section{Outcomes}

We considered five outcomes: antiviral treatment status, response to antivirals, cirrhosis, loss to followup, and mortality. Persons were considered to have been treated if they had ever received any medication against HCV. Virologic response to therapy was classified as sustained virologic response (SVR) or failure, and was based on viral load assessment after the end of the most recent treatment, regardless of the type of treatment. Failure was defined as any detectable HCV RNA after treatment end. Persons who had undetectable HCV RNA 12 weeks after the end of treatment were deemed to have achieved SVR. We excluded from the analysis persons whose HCV RNA was measured only before or during treatment. Persons were considered lost to follow-up (LTFU) if their last visit was more than 2 years before the closing date of the analysis (December $31^{\text {st }}$ 2014), unless they had died. The analysis of LTFU only included persons registered $\geq 2$ years before the closing date.

\section{Statistical Analysis}

We performed Laplace regressions [22] for time to event analyses (cirrhosis, loss to follow-up and mortality). We measured time from enrolment into the cohort until the date of the event, last follow-up visit, or death (whichever occurred first). We censored our analysis after 5 years of follow-up because few persons were followed for more than 5 years. We performed logistic regression to determine treatment status and virologic response, and adjusted our analyses for the following variables: time since diagnosis, HCV genotype, co-infection with HIV, chronic co-infection with HBV, and study site. Models for loss to follow-up, mortality, treatment status and virologic response were also adjusted for cirrhosis at enrolment (Figure 1). Persons whose HIV status was missing were considered HIV-negative. We used Cox models for 
sensitivity analysis, and used multiple imputation for all missing values of explanatory variables. We imputed missing values with chained equations for 20 imputed datasets. We used the following variables in imputation equations: HIV, chronic HBV, HCV genotype, time since diagnosis, cirrhosis at enrolment, LCA groups, study site, the binary indicator for the event, and the Nelson-Aalen estimator of the cumulative hazard to the survival time [23]. We also performed a complete case analysis, excluding persons with any missing covariable. Results are presented as time to event (years) or odds ratio (OR). We used Stata software (version 13.1, Stata Corporation, College Station, Texas, USA, 2013) for analyses. 


\section{Results}

A total of 4,488 SCCS persons were included in the study. The majority were males ( $n=2,830 ; 63.1 \%)$, Swiss $(3,292 ; 73.4 \%)$, and over half were PWID (2,530; 56.5\%), of which $493(19.5 \%)$ were former drug users (Table 1, Table 4 in supplementary material). Median age at enrolment was 43 years (IQR 36-51 years). Almost half of the persons had genotype $1(2,166 ; 48.3 \%)$, more than a quarter had genotype $3(1,183$; 26.4\%), genotype 4 was the next most common (422;9.4\%), followed by genotype 2 (354; 7.9\%). The percentage of missing values was generally low (maximum 1.5\%), except for HIV co-infection (21\%), HBV co-infection (9\%) and HCV genotype (8\%).

\section{Socio-behavioural groups identified by latent class analysis}

Based on the LCA, we chose a five-class model because it had a smaller BIC value than models with fewer or more classes. The BIC is one of the most common criteria for model selection among a finite set of models; the model with the lowest BIC is preferred [21]. Figure 2 shows how groups with corresponding BIC values developed as the number of classes increased. The group "PWID" was the first group we identified (G1 in model 2). The second group (G2 in model 2) later split into "Swiss employees" and "retirees". For 2,530 (56.4\%) persons, the probability of belonging to the group they were assigned to was $\geq 0.80$, for $845(18.8 \%)$ persons, this probability was $<0.60$, so group allocation was less certain. The "Swiss employees" included a few unemployed persons (35/1129; 3.1\%), and "PWID" contained a few persons with no history of injecting drug use (non-PWID; 16/1642; 1.0\%). The two groups, "foreign employees" and "retirees", incorporated some PWID (38/497; 7.6\%) and moderate to heavy drinkers (56/599, 9.3\%). Median membership probability ranged from 0.61 (IQR 0.57-0.64) in "male drinkers" to 0.99 (IQR 0.94 1.00) in "retirees". Box 1 summarizes the groups we found through LCA. Table 1 shows the characteristics of the groups. Results were similar in the sensitivity analysis when former and current PWID were split into two categories (Table 4, supplementary material).

\section{Outcomes}

All 4,488 persons were included in our analysis of treatment status and over half $(2,436 ; 54.3 \%)$ received treatment. The percentage of treatment uptake was lower in "PWID" (732; 44.6\%), higher in "Swiss employees" (641; 56.8\%) and around 60\% for the other groups: "male drinkers" (381; 61.3\%), "foreign employees" (316; 63.6\%) and "retirees" (366; 61.1\%). The odds ratio to be treated was significantly lower 
for "PWID" (adjusted OR 0.54, 95\% Cl 0.42-0.69) and for "retirees" (adjusted OR 0.69, 95\% Cl 0.51-0.92) compared to "foreign employees" (Table 2). A total of 1,967 (43.8\%) persons were included in our analysis of virologic response; of these, almost half $(957 ; 48.6 \%)$ had achieved SVR. The "retirees" had the lowest percentage of SVR (103; 34.3\%), while SVR was highest in "PWID" (326; 55.8\%) and "foreign employees" (140; 55.8\%). Almost half of "Swiss employees" (260; 48.7\%) achieved SVR and this percentage was slightly lower in "male drinkers" (128; 42.9\%). The odds ratio of reaching SVR was lower in "retirees" than in "foreign employees" (adjusted OR $=0.48,95 \% \mathrm{Cl} 0.32-0.72$; Table 2), but no difference was apparent for other groups. A total of 237 (5.3\%) persons died, 1,364 (30.4\%) were lost to follow-up, and 897 (20.0\%) developed cirrhosis. Table 2 shows the corresponding estimated median time from enrolment to these events calculated with Laplace regression. The adjusted median time to death was similar across groups, ranging from 8.7 years after enrolment in "male drinkers" to 10.1 years in "Swiss employees". The overall median adjusted time to loss to follow-up was 5.4 years after enrolment, but was significantly longer in "Swiss employees" (6.0 years). In other groups, median adjusted time ranged between 4.8 ("PWID") and 5.9 years ("retirees"). "Swiss employees" took the longest time to develop cirrhosis after enrolment (9.5 years), and it developed soonest in "retirees" (5.0 years) and "male drinkers" (6.1 years). Results were similar when we conducted sensitivity analyses, trying different approaches to handle missing data (Table 3). 


\section{Discussion}

\section{Main findings}

LCA revealed five distinct socio-behavioural groups of HCV-infected persons enrolled in the SCCS. The groups had different characteristics at enrolment, and different outcomes for treatment status, virologic response, development of cirrhosis, loss to follow-up, and death.

\section{Groups of persons with (a history of) injecting drug use}

Since PWID are the largest HCV risk group in Switzerland, it is no surprise they were the biggest LCA group ( $37 \%$ of all persons). They had characteristics that are frequently reported for PWID, including young age $[11,24,25]$, a lower percentage of women (32\%) [14] than in the overall population, high unemployment $(23 \%)[24,26]$, and previous or ongoing moderate to heavy alcohol consumption $(61 \%)[10,24-26]$. We identified two more groups with a high rate of PWID: "male drinkers" and "Swiss employees", with 69\% and $39 \%$ of persons with a history of injecting drug use respectively. These two groups include more "integrated" PWID who are well educated ( $96 \%$ and $92 \%$ persons with medium to high level of education) and likely to be employed (63\% and $96 \%)$.

\section{Groups of persons without (a history of) injecting drug use}

People who did not acquire HCV via intravenous drug use were frequently documented among "foreign employees" and "retirees". Most HCV infections in resource-limited countries are caused by unsafe medical procedures $[27,28]$. In the European birth countries of many Swiss immigrants, healthcareassociated infections were also common at some points in time; e.g. in Italy and Spain, healthcareassociated infections were frequent from 1950 to 1970 [4,29-32].

\section{Treatment outcomes and access to therapy}

Group membership was associated with relevant outcomes like cirrhosis, loss to follow-up and mortality. Among all groups, "male drinkers", despite their young age (median age: 48 years old), had the shortest time to death and second shortest time to cirrhosis after being enrolled. We suppose that alcohol is the decisive factor, with $100 \%$ ongoing or former moderate to high alcohol consumption. Alcohol-associated liver disease may also have caused their poor treatment outcome: despite the second-highest treatment 
rate, "male drinkers" had the second-worst treatment response. The "PWID" group had the shortest time to loss to follow-up after enrolment. This was expected, as PWID are more prone to miss appointments [33]. "PWID" was also the youngest group, so its members may be more mobile. Despite their youth, mortality in this group was relatively high and time to death was close to the overall median time to death across all groups. We assume that death was mostly caused by drug-related illness or accidents. HCVassociated disease progresses more slowly in young people, so treatment may have been postponed. Alternatively treatment may have been delayed because interferon- $\alpha$ (IFN- $\alpha$ ) has major psychiatric side effects and PWID often have psychiatric comorbidities $[10,24]$. But when they were treated, these persons had the second-highest virologic response. This finding is in line with publications that showed comparable treatment success in PWID and in people who do not inject drugs $[10,11,24,26]$.

"Retirees" developed cirrhosis in the shortest period of time and had the second shortest time to death. A high proportion of "retirees" were in an advanced stage of liver disease at enrolment. These persons were probably diagnosed late, since awareness about HCV in older people is low in the general population and among clinicians. Older age is also a risk factor for faster progression of liver disease and cirrhosis [13]. Our study confirmed that old people are persons with little loss to follow-up, but despite this and the higher rate of cirrhosis, treatment uptake among "retirees" was low. Clinicians may have been reluctant to treat old persons with IFN- $\alpha$ and ribavirin (RBV) because in old persons treatment-related anaemia is more frequent and its consequences more severe [13].

"Foreign employees" and "Swiss employees" presented quite similar results. Both groups had the longest time to death and the longest time to cirrhosis, probably reflecting a combined effect of their young age and low alcohol consumption. Treatment status and virologic response were not significantly different, perhaps because both have good access to healthcare.

Access to antiviral therapy was similar across groups, which is not surprising in view of the limited choice of medicaments during many years. The decision when and how to treat was based on the estimated treatment need, anticipated side effects and cure rates of the drugs available at the time the persons were treated. DAAs were rarely used $(2.4 \%$ overall) probably because reimbursement for the first DAA substance started in August 2014 in Switzerland. DAA use was more frequent in "retirees" and "male drinkers". These groups had the highest proportion of persons in Metavir stage F3 or F4 at enrolment into the cohort (25\% and $24 \%)$ and by far the highest rate of advancement to cirrhosis. Thus, there was an urgent treatment need, and they were entitled to obtain DAA which, up to the date of censoring, in Switzerland had been restricted to persons in Metavir stage F3 and F4. 


\section{Strengths and Weaknesses}

The SCCS includes only a limited proportion of all HCV-infected persons in Switzerland, the total number of infections being estimated at 82,700 in 2013 [3]. However, patient characteristics are comparable to official national notification data [19], so our results should be generalizable to HCV-infected persons in Switzerland and possibly other countries with similar socio-economic characteristics.

The information collected at enrolment into the SCCS covers a wide range of socio-behavioural variables. The decision which variables to include in the LCA was subjective, but was done a priori. We found median probability of belonging to the "male drinkers" group was rather low $(p=0.61)$ and there was some chance that persons assigned to this group could potentially belong to the "Swiss employees" or "PWID" groups. But membership probabilities for the other groups were high, and the model was able to create heterogeneous groups. LCA is based on a likelihood-based model and uses objective criteria to determine the best fit i.e. the optimal number of classes. LCA can also easily deal with categorical data and missing values.

In general, only a small proportion of values in the socio-behavioural variables was missing $(<1.5 \%$ for all variables). The proportion of missing values was higher for some covariables we included in the multivariable analyses (HIV co-infection 21\%, chronic HBV co-infection $9 \%$ and HCV genotype $8 \%$ ). Probably persons with missing HIV values were more likely to be HIV-negative, and we therefore considered them to be negative. However, in the sensitivity analysis where we used multiple imputation, and in the complete case analysis (where persons with missing values were excluded), results were similar. We used the date of diagnosis rather than the date of infection, as the time of infection was often unknown. PWID were probably diagnosed and enrolled earlier into the cohort than persons of other risk groups. It is therefore not surprising that non-PWID were in a more advanced stage of the disease at enrolment. In the main analyses we combined former and current PWID in one group since both groups are equally at risk of HCV infection. However, results were similar in the sensitivity analysis where people were categorized into "no", "former" and "current" PWID.

Defining virologic response was difficult, since HCV RNA values were often not recorded at the recommended time points, or the date the patient stopped therapy was missing. Nevertheless, we were able to clearly classify the virologic response of the majority of persons (96\%) we included in the analysis. We were also limited by self-reporting of data on drug use and alcohol consumption, which may have been biased by social desirability and recall. About $5 \%$ of persons were reported to have died, but deaths were probably underreported and persons lost to follow-up may have died. 


\section{Implications of findings and future research}

We used a person-centred approach to identify groups of persons with similar characteristics. Our approach reflects more closely the process of clinical decision-making, where clinicians use patient characteristics to decide who should be tested for HCV and how to optimize care in diagnosed persons. We identified two groups that do not conform to common assumptions about persons with chronic hepatitis C, while presenting at an advanced stage of the disease and with bad treatment outcomes. The "male drinkers" have high substance use, but are also well educated and likely to be employed. If, in the population, persons with these characteristics do not volunteer information about drug use, the clinician may not ask questions concerning injecting drug use (and a possibly associated HCV infection). There is thus a risk of under-diagnosis especially if these persons are not currently using drugs. Similarly, retirees, frequently infected outside intravenous drug use, may also be underdiagnosed. The proportion of persons with advanced liver disease is high at enrolment into the cohort in both of these groups.

\section{Conclusions}

Using LCA, we were able to identify groups of persons with delayed access to care and poor treatment outcomes. LCA may therefore be a powerful tool for identifying high-risk subgroups that may be missed with a single-variable approach. This information may be useful to design targeted interventions. 


\section{Acknowledgement}

This work was supported by Swiss National Science Foundation grants 3347C0-108782/1 and 33CS30148417/1 to the Swiss Hepatitis C Cohort Study and unrestricted grants to the Swiss Hepatitis C Cohort Study Foundation by AbbVie, Gilead, Bristol Myers Squibb, Janssen-Cilag, MSD, Novartis, Roche Pharma Switzerland and Roche Diagnostics. Olivia Keiser was funded by a PROSPER fellowship grant (150934) from the Swiss National Science Foundation. The funding parties had no role in study design, data collection and analysis, decision to publish, or preparation of the manuscript. We thank Ben Spycher and Zofia Baranczuk for their support. We also thank Kali Tal for her editorial assistance. 


\section{References}

1. Razavi H, Waked I, Sarrazin C, Myers RP, Idilman R, Calinas F, et al. The present and future disease burden of hepatitis C virus (HCV) infection with today's treatment paradigm. J Viral Hepat. 2014 May;21 Suppl 1:34-59.

2. Fretz R, Negro F, Bruggmann P, Lavanchy D, De Gottardi A, Pache I, et al. Hepatitis B and C in Switzerland - healthcare provider initiated testing for chronic hepatitis B and C infection. Swiss Med Wkly. 2013;143:w13793.

3. Müllhaupt B, Bruggmann P, Bihl F, Blach S, Lavanchy D, Razavi H, et al. Modeling the Health and Economic Burden of Hepatitis C Virus in Switzerland. PloS One. 2015;10(6):e0125214.

4. Cornberg M, Razavi HA, Alberti A, Bernasconi E, Buti M, Cooper C, et al. A systematic review of hepatitis $C$ virus epidemiology in Europe, Canada and Israel. Liver Int Off J Int Assoc Study Liver. 2011 Jul;31 Suppl 2:30-60.

5. Wedemeyer H, Dore GJ, Ward JW. Estimates on HCV disease burden worldwide - filling the gaps. J Viral Hepat. 2015 Jan;22 Suppl 1:1-5.

6. Pawlotsky J-M. New hepatitis $C$ therapies: the toolbox, strategies, and challenges. Gastroenterology. 2014 May;146(5):1176-92.

7. Meyer JP, Moghimi Y, Marcus R, Lim JK, Litwin AH, Altice FL. Evidence-based interventions to enhance assessment, treatment, and adherence in the chronic Hepatitis $\mathrm{C}$ care continuum. Int J Drug Policy. 2015 May 17;

8. Negro F. Der Kampf gegen Hepatitis B und C: ein Notfall für die öffentliche Gesundheit in der Schweiz. Schweizerische Ärztezeitung. 2013;94:27-8.

9. Negro F. Epidemiology of hepatitis C in Europe. Dig Liver Dis Off J Ital Soc Gastroenterol Ital Assoc Study Liver. 2014 Dec 15;46 Suppl 5:S158-64.

10. Hellard M, Sacks-Davis R, Gold J. Hepatitis $C$ treatment for injection drug users: a review of the available evidence. Clin Infect Dis Off Publ Infect Dis Soc Am. 2009 Aug 15;49(4):561-73.

11. Arain A, Robaeys G. Eligibility of persons who inject drugs for treatment of hepatitis $C$ virus infection. World J Gastroenterol WJG. 2014 Sep 28;20(36):12722-33.

12. Wiessing L, Ferri M, Grady B, Kantzanou M, Sperle I, Cullen KJ, et al. Hepatitis C virus infection epidemiology among people who inject drugs in Europe: a systematic review of data for scaling up treatment and prevention. PloS One. 2014;9(7):e103345.

13. Vespasiani-Gentilucci U, Galati G, Gallo P, De Vincentis A, Riva E, Picardi A. Hepatitis C treatment in the elderly: New possibilities and controversies towards interferon-free regimens. World J Gastroenterol WJG. 2015 Jun 28;21(24):7412-26.

14. Burton MJ, Brock JB, Geraci SA. Women with chronic hepatitis C virus infection: recommendations for clinical practice. South Med J. 2013 Jul;106(7):422-6. 
15. Bruggmann P, Dampz M, Gerlach T, Kravecz L, Falcato L. Treatment outcome in relation to alcohol consumption during hepatitis $C$ therapy: an analysis of the Swiss Hepatitis C Cohort Study. Drug Alcohol Depend. 2010 Jul 1;110(1-2):167-71.

16. Devantier SL, Minda JP, Hadarra W, Goldszmidt M. Physicians' Use of Deep Features: Expertise Differences in Patient Categorization. In: Proceedings of the 30th Annual Conference of the Cognitive Science Society. 2008.

17. Cheryl Lewis RN. Bedside manners: Myth of the Doctor - Patient Relationship. Bloomington, IN, USA: 1st Book Library; 2003.

18. Lazarsfeld R, Henry NW. Latent Structure Analysis. Boston: Houghton Mifflin; 1968.

19. Prasad L, Spicher VM, Zwahlen M, Rickenbach M, Helbling B, Negro F, et al. Cohort Profile: the Swiss Hepatitis C Cohort Study (SCCS). Int J Epidemiol. 2007 Aug;36(4):731-7.

20. Swiss Conference of Cantonal Ministers of Education website [Internet]. [cited 2016 Feb 1]. Available from: http://www.edk.ch/dyn/16833.php

21. McLachlan G, Peel D. Finite mixture models. New York: John Wiley \& Sons; 2000.

22. Bottai M, Zhang J. Laplace regression with censored data. Biom J Biom Z. 2010 Aug;52(4):487-503.

23. White IR, Royston P. Imputing missing covariate values for the Cox model. Stat Med. 2009 Jul 10;28(15):1982-98.

24. Robaeys G, Grebely J, Mauss S, Bruggmann P, Moussalli J, De Gottardi A, et al. Recommendations for the management of hepatitis $C$ virus infection among people who inject drugs. Clin Infect Dis Off Publ Infect Dis Soc Am. 2013 Aug;57 Suppl 2:S129-37.

25. Bruggmann $P$, Grebely J. Prevention, treatment and care of hepatitis $C$ virus infection among people who inject drugs. Int J Drug Policy. 2015 Feb;26 Suppl 1:S22-6.

26. Mravčík V, Strada L, Stolfa J, Bencko V, Groshkova T, Reimer J, et al. Factors associated with uptake, adherence, and efficacy of hepatitis $C$ treatment in people who inject drugs: a literature review. Patient Prefer Adherence. 2013;7:1067-75.

27. Hajarizadeh B, Grebely J, Dore GJ. Epidemiology and natural history of HCV infection. Nat Rev Gastroenterol Hepatol. 2013 Sep;10(9):553-62.

28. Prati D. Transmission of hepatitis $\mathrm{C}$ virus by blood transfusions and other medical procedures: a global review. J Hepatol. 2006 Oct;45(4):607-16.

29. Alter MJ. Epidemiology of hepatitis C virus infection. World J Gastroenterol WJG. 2007 May 7;13(17):2436-41.

30. Chiaramonte M, Stroffolini T, Lorenzoni U, Minniti F, Conti S, Floreani A, et al. Risk factors in community-acquired chronic hepatitis $\mathrm{C}$ virus infection: a case-control study in Italy. J Hepatol. 1996 Feb;24(2):129-34. 
31. Riestra S, Fernández E, Leiva $P$, García $S$, Ocio G, Rodrigo L. Prevalence of hepatitis C virus infection in the general population of northern Spain. Eur J Gastroenterol Hepatol. 2001 May;13(5):477-81.

32. Bruguera M, Forns X. [Hepatitis C in Spain]. Med Clínica. 2006 Jun 17;127(3):113-7.

33. Bruggmann $\mathrm{P}$, Litwin $\mathrm{AH}$. Models of care for the management of hepatitis $\mathrm{C}$ virus among people who inject drugs: one size does not fit all. Clin Infect Dis Off Publ Infect Dis Soc Am. 2013 Aug;57 Suppl 2:S56-61. 
Table 1: Participant characteristics in the socio-behavioural groups identified by the latent class analysis

\begin{tabular}{|c|c|c|c|c|c|c|}
\hline & $\begin{array}{c}\text { Swiss } \\
\text { employees }\end{array}$ & PWID & $\begin{array}{c}\text { Male } \\
\text { drinkers }\end{array}$ & $\begin{array}{c}\text { Foreign } \\
\text { employees }\end{array}$ & Retirees & Total \\
\hline No. of participants (\%) & $1,129(25.2)$ & $1,642(36.6)$ & $621(13.8)$ & $497(11.1)$ & $599(13.3)$ & $4,488(100.0)$ \\
\hline No. of women & $618(54.7)$ & $526(32.0)$ & $6(1.0)$ & $203(40.8)$ & $305(50.9)$ & 1,658 (36.9) \\
\hline $\begin{array}{l}\text { Median (interquartile range) } \\
\text { age, years }\end{array}$ & $44(38-50)$ & $37(32-42)$ & $48(44-52)$ & $41(35-49)$ & $64(60-68)$ & $43(36-51)$ \\
\hline Swiss nationality & 1,113 (98.6) & $1,252(76.2)$ & $522(84.1)$ & $0(0.0)$ & $405(67.6)$ & $3,292(73.4)$ \\
\hline \multicolumn{7}{|l|}{ Education $^{\mathrm{a}}$} \\
\hline lower & $77(6.8)$ & $603(36.7)$ & $14(2.2)$ & $138(27.8)$ & $134(22.4)$ & $966(21.8)$ \\
\hline medium & $689(61.0)$ & $1,001(61.0)$ & $450(72.5)$ & $200(40.2)$ & $334(55.8)$ & $2,674(60.5)$ \\
\hline higher & 344 (30.5) & $20(1.2)$ & $148(23.8)$ & $150(30.2)$ & 119 (19.9) & $781(17.7)$ \\
\hline \multicolumn{7}{|l|}{ Occupational situation } \\
\hline worker/student & $1,078(95.5)$ & $687(41.8)$ & $394(63.4)$ & 447 (89.9) & $131(21.9)$ & $2,737(61.3)$ \\
\hline retired/social assistance & $10(0.9)$ & $563(34.3)$ & $192(30.9)$ & $9(1.8)$ & $462(77.1)$ & $1,236(27.7)$ \\
\hline unemployed & $35(3.1)$ & $385(23.4)$ & $33(5.3)$ & $37(7.4)$ & $3(0.5)$ & $493(11.0)$ \\
\hline \multicolumn{7}{|l|}{ Alcohol consumption ${ }^{b}$} \\
\hline no or light drinker & 979 (86.7) & $637(38.8)$ & $0(0.0)$ & $375(75.4)$ & $442(73.8)$ & $2,433(54.2)$ \\
\hline moderate-heavy drinker & $39(3.4)$ & $331(20.2)$ & $211(34.0)$ & $26(5.2)$ & $56(9.3)$ & $663(14.8)$ \\
\hline former moderate-heavy drinker & $111(9.8)$ & $674(41.0)$ & $410(66.0)$ & $96(19.3)$ & $101(16.9)$ & 1,392 (31.0) \\
\hline Drug use (former or ongoing) ${ }^{c}$ & $437(38.7)$ & $1,625(99.0)$ & $429(69.1)$ & $38(7.6)$ & $1(0.2)$ & $2,530(56.5)$ \\
\hline Recorded HCV risk factors ${ }^{d}$ & $911(80.7)$ & $1,353(82.4)$ & $531(85.5)$ & $373(75.1)$ & $456(76.1)$ & $3,624(80.7)$ \\
\hline \multicolumn{7}{|l|}{ Antiviral therapy } \\
\hline Peginterferon/Ribavirin & $596(52.8)$ & $693(42.2)$ & $340(54.7)$ & $287(57.7)$ & $324(54.1)$ & $2,240(49.9)$ \\
\hline Boceprevir/Telaprevir & $14(1.2)$ & $7(0.4)$ & $9(1.5)$ & $10(2.0)$ & $6(1.0)$ & $46(1.0)$ \\
\hline DAA & $21(1.9)$ & $23(1.4)$ & $21(3.4)$ & $14(2.8)$ & $27(4.5)$ & $106(2.4)$ \\
\hline \multicolumn{7}{|l|}{ Fibrosis (stage) } \\
\hline FO & 89 (7.9) & $88(5.4)$ & $26(4.2)$ & $31(6.2)$ & $31(5.2)$ & 265 (5.9) \\
\hline F1 & 209 (18.5) & 245 (14.9) & $76(12.2)$ & $112(22.5)$ & $62(10.3)$ & 704 (15.7) \\
\hline F2 & $183(16.2)$ & 235 (14.3) & $87(14.0)$ & $61(12.3)$ & $91(15.2)$ & 657 (14.6) \\
\hline F3 & 69 (6.1) & $73(4.4)$ & $57(9.2)$ & $44(8.8)$ & $55(9.2)$ & $298(6.6)$ \\
\hline F4 & 85 (7.5) & $108(6.6)$ & $93(15.0)$ & $51(10.3)$ & 96 (16.0) & 433 (9.6) \\
\hline
\end{tabular}

PWID: persons who inject drugs

${ }^{a}$ Education: defined according to the Swiss Conference of Cantonal Ministers of Education.

${ }^{b}$ Alcohol consumption: no or light drinker ( $\leq 20 \mathrm{~g}$ alcohol/day), moderate-heavy drinker (>20 $\mathrm{g}$ alcohol/day) and former moderate-heavy drinker (used to drink >20 g alcohol/day before, but currently stopped).

${ }^{\mathrm{c}}$ Drug use: ever injected drugs.

${ }^{d}$ Recorded HCV risk factors: medical procedures, intranasal drugs, transfusion, high risk sexual behaviour, partner HCV positive, accidental needle prick, profession in contact with blood, HCV positive person in household, piercing and/or tattoo. 
Table 2: Treatment status, response to antivirals and time (in years) to cirrhosis/loss to follow-up/death by LCA groups

\begin{tabular}{|c|c|c|c|c|c|c|c|c|c|c|}
\hline & \multicolumn{5}{|c|}{ Treatment status } & \multicolumn{5}{|c|}{ Response to antivirals } \\
\hline & $\begin{array}{c}\mathrm{N}=4,488 \\
\text { Unadjusted OR } \\
(95 \% \mathrm{Cl})\end{array}$ & $p$ & \multicolumn{2}{|c|}{$\begin{array}{c}\mathrm{N}=3,768 \\
\text { Adjusted }^{\mathrm{a}} \text { OR } \\
(95 \% \mathrm{Cl})\end{array}$} & \multirow[t]{2}{*}{$\mathrm{p}$} & $\begin{array}{c}\mathrm{N}=1,967 \\
\text { Unadjusted OR } \\
(95 \% \mathrm{Cl})\end{array}$ & \multicolumn{3}{|c|}{$\begin{array}{cc} & \mathrm{N}=1,785 \\
& \text { Adjusted }^{\mathrm{a}} \text { OR } \\
\mathrm{p} & (95 \% \mathrm{Cl})\end{array}$} & $p$ \\
\hline \multicolumn{10}{|l|}{$\begin{array}{l}\text { Socio-behavioural } \\
\text { groups }\end{array}$} & \\
\hline Foreign employees & \multicolumn{2}{|l|}{1} & \multicolumn{2}{|c|}{1} & \multicolumn{2}{|r|}{1} & \multicolumn{4}{|c|}{1} \\
\hline Swiss employees & $0.75(0.61 ; 0.94)$ & 0.010 & \multicolumn{2}{|c|}{$0.85(0.66 ; 1.09)$} & 0.191 & $0.75(0.56 ; 1.02)$ & 0.064 & \multicolumn{2}{|c|}{$0.78(0.55 ; 1.10)$} & 0.152 \\
\hline PWID & $0.46(0.37 ; 0.57)$ & $<0.001$ & \multicolumn{2}{|c|}{$0.54(0.42 ; 0.69)$} & $<0.001$ & $1.00(0.74 ; 1.35)$ & 0.990 & \multicolumn{2}{|c|}{$0.93(0.66 ; 1.31)$} & 0.675 \\
\hline Male drinkers & $0.91(0.71 ; 1.16)$ & 0.445 & \multicolumn{2}{|c|}{$0.93(0.69 ; 1.24)$} & 0.602 & $0.60(0.43 ; 0.84)$ & 0.003 & \multicolumn{2}{|c|}{$0.70(0.47 ; 1.03)$} & 0.071 \\
\hline \multirow[t]{3}{*}{ Retirees } & $0.90(0.70 ; 1.15)$ & 0.399 & \multicolumn{2}{|c|}{$0.69(0.51 ; 0.92)$} & 0.012 & $0.41(0.29 ; 0.59)$ & $<0.001$ & \multicolumn{2}{|c|}{$0.48(0.32 ; 0.72)$} & $<0.001$ \\
\hline & \multicolumn{3}{|c|}{ Time to cirrhosis } & \multicolumn{3}{|c|}{ Time to loss to follow-up } & \multicolumn{4}{|c|}{ Time to death } \\
\hline & $\begin{array}{c}\begin{array}{c}\text { Unadjusted } \\
\text { msp }\end{array} \\
\mathrm{N}=4,458\end{array}$ & \multicolumn{2}{|c|}{$\begin{array}{c}\text { Adjusted }^{b} \\
\text { msp } \\
N=3,769\end{array}$} & \multicolumn{2}{|c|}{$\begin{array}{l}\text { Unadjusted } \\
\text { msp } \\
\mathrm{N}=4,054\end{array}$} & $\begin{array}{c}\text { Adjusted }^{c} \\
\text { msp } \\
\mathrm{N}=3,491 \\
\end{array}$ & \multicolumn{2}{|c|}{$\begin{array}{c}\text { Unadjusted } \\
\text { msp } \\
N=4,482\end{array}$} & \multicolumn{2}{|c|}{$\begin{array}{c}\text { Adjusted }^{c} \\
\text { msp } \\
N=3,763\end{array}$} \\
\hline \multicolumn{11}{|l|}{$\begin{array}{l}\text { Socio-behavioural } \\
\text { groups }\end{array}$} \\
\hline Foreign employees & 7.8 & \multicolumn{2}{|c|}{8.4} & \multicolumn{2}{|c|}{5.8} & 5.3 & \multicolumn{2}{|c|}{9.6} & \multicolumn{2}{|c|}{9.4} \\
\hline Swiss employees & $0.5(-0.4 ; 1.3)$ & \multicolumn{2}{|c|}{$1.1(0.2 ; 2.1)$} & \multicolumn{2}{|c|}{$0.5(0.0 ; 0.9)$} & $0.7(0.2 ; 1.2)$ & $1.1(-\mathrm{C}$ & $.1 ; 2.4)$ & $0.7(-$ & $.5 ; 1.8)$ \\
\hline PWID & $-0.3(-1.1 ; 0.5)$ & $0.2(-0$ & $.7 ; 1.1)$ & $-0.5(-0$ & $.9 ;-0.1)$ & $-0.5(-1.0 ; 0.1)$ & $-0.3(-$ & $1.3 ; 0.8)$ & $-0.4(-$ & $1.5 ; 0.6)$ \\
\hline Male drinkers & $-2.4(-3.2 ;-1.6)$ & $-2.3(-3$ & $.4 ;-1.2)$ & 0.610 & $1 ; 1.1)$ & $0.4(-0.2 ; 1.0)$ & $-1.7(-2$ & $.8 ;-0.6)$ & $-0.7(-$ & $1.8 ; 0.3)$ \\
\hline Retirees & $-2.6(-3.4 ;-1.7)$ & $-3.4(-4$ & $.6 ;-2.1)$ & 0.910 & $3 ; 1.4)$ & $0.6(0.0 ; 1.3)$ & $-1.5(-2$ & $2.6 ;-0.4)$ & $-0.6(-$ & $1.6 ; 0.5)$ \\
\hline
\end{tabular}

PWID: persons who inject drugs (former or current)

Treatment status and response to antivirals using logistic regression

OR: odds ratio with $95 \%$ confidence interval $(\mathrm{Cl})$

${ }^{a}$ Adjusted for: HCV genotype, cirrhosis at enrolment, time since diagnosis, chronic HBV infection, HIV infection, study site

Time to cirrhosis, time to lost to follow-up and time death using Laplace regression

$\mathrm{msp}=$ median survival percentile (50th); time to event calculated from enrolment

${ }^{\mathrm{b}}$ Adjusted for: time since diagnosis, HCV genotype, chronic HBV infection, HIV infection, study site

${ }^{c}$ Adjusted for: cirrhosis, time since diagnosis, HCV genotype, chronic HBV infection, HIV infection, study site 
Table 3: Sensitivity analyses

\begin{tabular}{|c|c|c|c|c|c|c|}
\hline \multirow[t]{3}{*}{ Groups } & \multirow[t]{3}{*}{ Analyses } & \multicolumn{5}{|c|}{ Outcomes } \\
\hline & & Cirrhosis & Loss to follow-up & Mortality & $\begin{array}{l}\text { Treatment } \\
\text { status }\end{array}$ & $\begin{array}{l}\text { Response to } \\
\text { antivirals }\end{array}$ \\
\hline & & $\mathrm{HR}(95 \% \mathrm{Cl})$ & $\mathrm{HR}(95 \% \mathrm{Cl})$ & $\mathrm{HR}(95 \% \mathrm{Cl})$ & OR $(95 \% \mathrm{Cl})$ & OR $(95 \% \mathrm{Cl})$ \\
\hline & 1 & $0.80(0.60 ; 1.06)$ & $0.77(0.62 ; 0.95)$ & $0.72(0.35 ; 1.47)$ & $0.85(0.66 ; 1.09)$ & $0.78(0.55 ; 1.10)$ \\
\hline \multirow[t]{3}{*}{ Swiss employees } & 2 & $0.79(0.58 ; 1.09)$ & $0.76(0.60 ; 0.97)$ & $0.89(0.40 ; 2.00)$ & $0.78(0.59 ; 1.05)$ & $0.90(0.61 ; 1.32)$ \\
\hline & 3 & $0.79(0.61 ; 1.04)$ & $0.80(0.66 ; 0.98)$ & $0.69(0.36 ; 1.32)$ & $0.80(0.63 ; 1.01)$ & $0.77(0.55 ; 1.07)$ \\
\hline & 1 & $0.83(0.63 ; 1.09)$ & $1.35(1.11 ; 1.64)$ & $2.01(1.07 ; 3.79)$ & $0.54(0.42 ; 0.69)$ & $0.93(0.66 ; 1.31)$ \\
\hline \multirow[t]{3}{*}{ PWID } & 2 & $0.81(0.60 ; 1.10)$ & $1.28(1.03 ; 1.59)$ & $2.17(1.06 ; 4.45)$ & $0.50(0.38 ; 0.66)$ & $0.94(0.65 ; 1.37)$ \\
\hline & 3 & $0.85(0.65 ; 1.09)$ & $1.40(1.17 ; 1.67)$ & $1.92(1.09 ; 3.37)$ & $0.46(0.37 ; 0.58)$ & $0.89(0.64 ; 1.25)$ \\
\hline & 1 & $1.89(1.43 ; 2.51)$ & $0.83(0.65 ; 1.07)$ & $2.40(1.26 ; 4.57)$ & $0.93(0.69 ; 1.24)$ & $0.70(0.47 ; 1.03)$ \\
\hline \multirow[t]{3}{*}{ Male drinkers } & 2 & $1.84(1.35 ; 2.51)$ & $0.79(0.60 ; 1.04)$ & $2.24(1.07 ; 4.71)$ & $0.90(0.65 ; 1.25)$ & $0.75(0.49 ; 1.15)$ \\
\hline & 3 & $1.90(1.46 ; 2.47)$ & $0.80(0.63 ; 1.01)$ & $2.35(1.32 ; 4.19)$ & $0.84(0.65 ; 1.09)$ & $0.67(0.47 ; 0.97)$ \\
\hline & 1 & $2.45(1.85 ; 3.25)$ & $0.85(0.66 ; 1.11)$ & $2.22(1.15 ; 4.27)$ & $0.69(0.51 ; 0.92)$ & $0.48(0.32 ; 0.72)$ \\
\hline \multirow[t]{2}{*}{ Retirees } & 2 & $2.41(1.75 ; 3.33)$ & $0.81(0.60 ; 1.11)$ & $2.76(1.30 ; 5.86)$ & $0.75(0.53 ; 1.06)$ & $0.51(0.32 ; 0.80)$ \\
\hline & 3 & $2.44(1.87 ; 3.17)$ & $0.83(0.65 ; 1.06)$ & $2.21(1.23 ; 3.98)$ & $0.73(0.56 ; 0.95)$ & $0.43(0.29 ; 0.63)$ \\
\hline
\end{tabular}

PWID: persons who inject drugs (former or current)

HR: hazard ratio with $95 \%$ confidence interval $(\mathrm{Cl})$

OR: odds ratio with $95 \%$ confidence interval (Cl)

Analysis 1: missing HIV status was assumed to be negative

Analysis 2: missing HIV status not replaced

Analysis 3: missing HIV status and other explanatory variables replaced by multiple imputation 


\section{Box 1: Summary description of the groups}

\section{1) Swiss employees $(n=1129,25 \%)$}

The median age at enrolment was 44 years (38-50 years). The majority were Swiss and employed with medium-high education. Most were no or light drinkers, but almost $40 \%$ were drug users. Gender was balanced. Median probability of belonging to the group: 0.92 (0.70-0.94).

2) PWID ( $n=1642,37 \%$ )

The median age at enrolment was 37 years (32-42 years). The majority were male and Swiss. They were drug users and $61 \%$ were current/former moderate-heavy drinkers. They had a medium-low education and $57 \%$ had social assistance or were unemployed. Median probability of belonging to the group: 0.85 (0.66-0.96).

\section{3) Male drinkers $(n=621,14 \%)$}

The median age at enrolment was 48 years ( $44-52$ years). $84 \%$ were Swiss and almost all male. All were current/former moderate-heavy drinkers and almost $70 \%$ were drug users. Median probability of belonging to the group: $0.61(0.57-0.64)$.

4) Foreign employees $(n=497,11 \%)$

The median age at enrolment was 41 years (35-49 years). All were foreigners and $41 \%$ were female. Nearly all members of this group were employed, the majority were no or light drinkers and a few were drug users. Median probability of belonging to the group: $0.76(0.68-0.86)$.

5) Retirees ( $n=599,13 \%$ )

The median age at enrolment was 64 years (60-68 years). The majority were retired, none were drug users and most of them were no or light drinkers. The gender was balanced and $68 \%$ were Swiss.

Median probability of belonging to the group: 0.99 (0.94-1.00).

PWID: persons who inject drugs

Drug use: ever injected drugs 
Figure 1: Selection of persons for the analyses

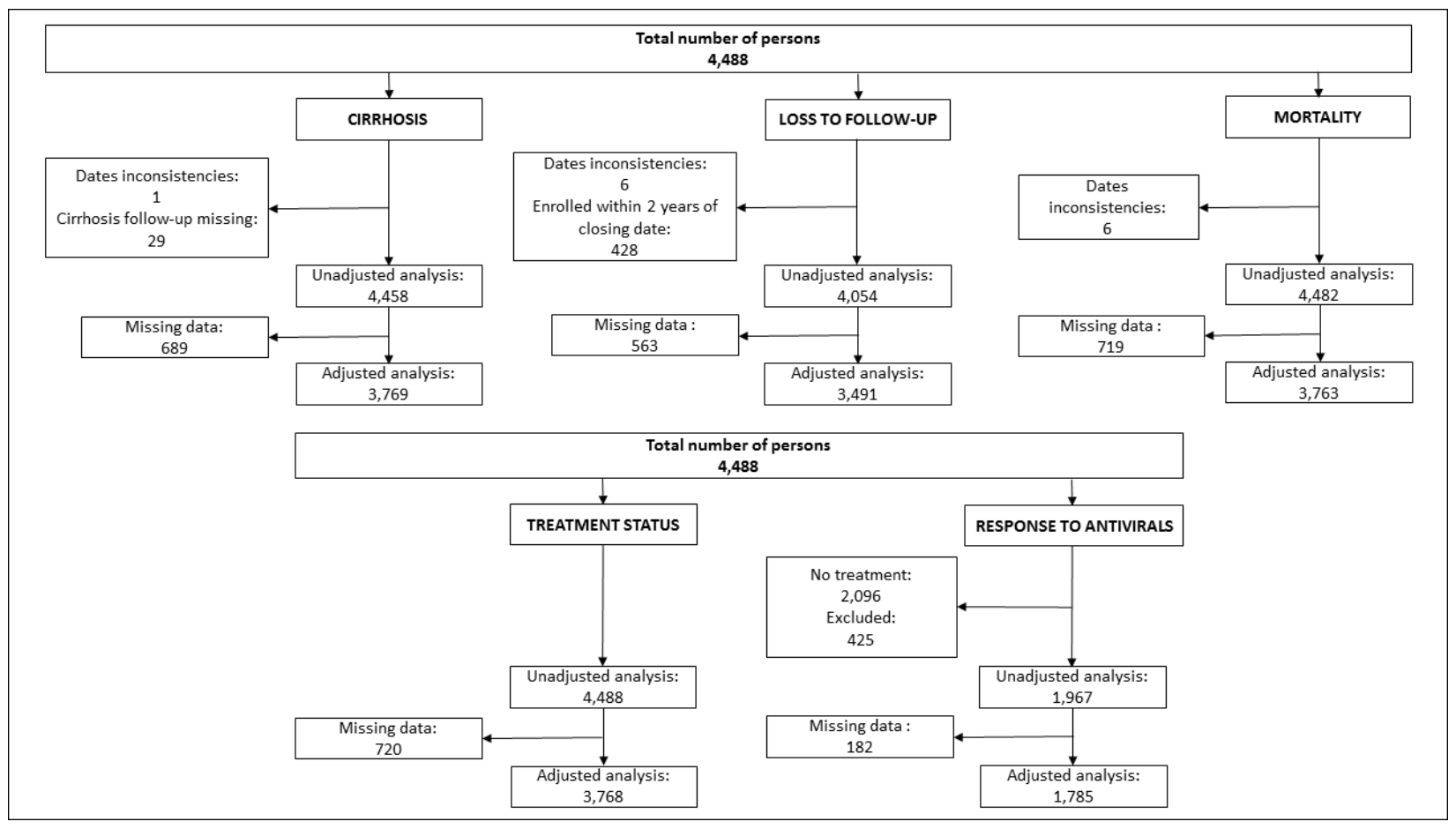


Figure 2: Stepwise identification of socio-behavioural groups in latent class analysis

The size of shaded boxes is proportional to the percentage of the 4,488 persons allocated to the groups. The five groups in the final model were assigned labels according to their most pertinent characteristics (see Box 1).

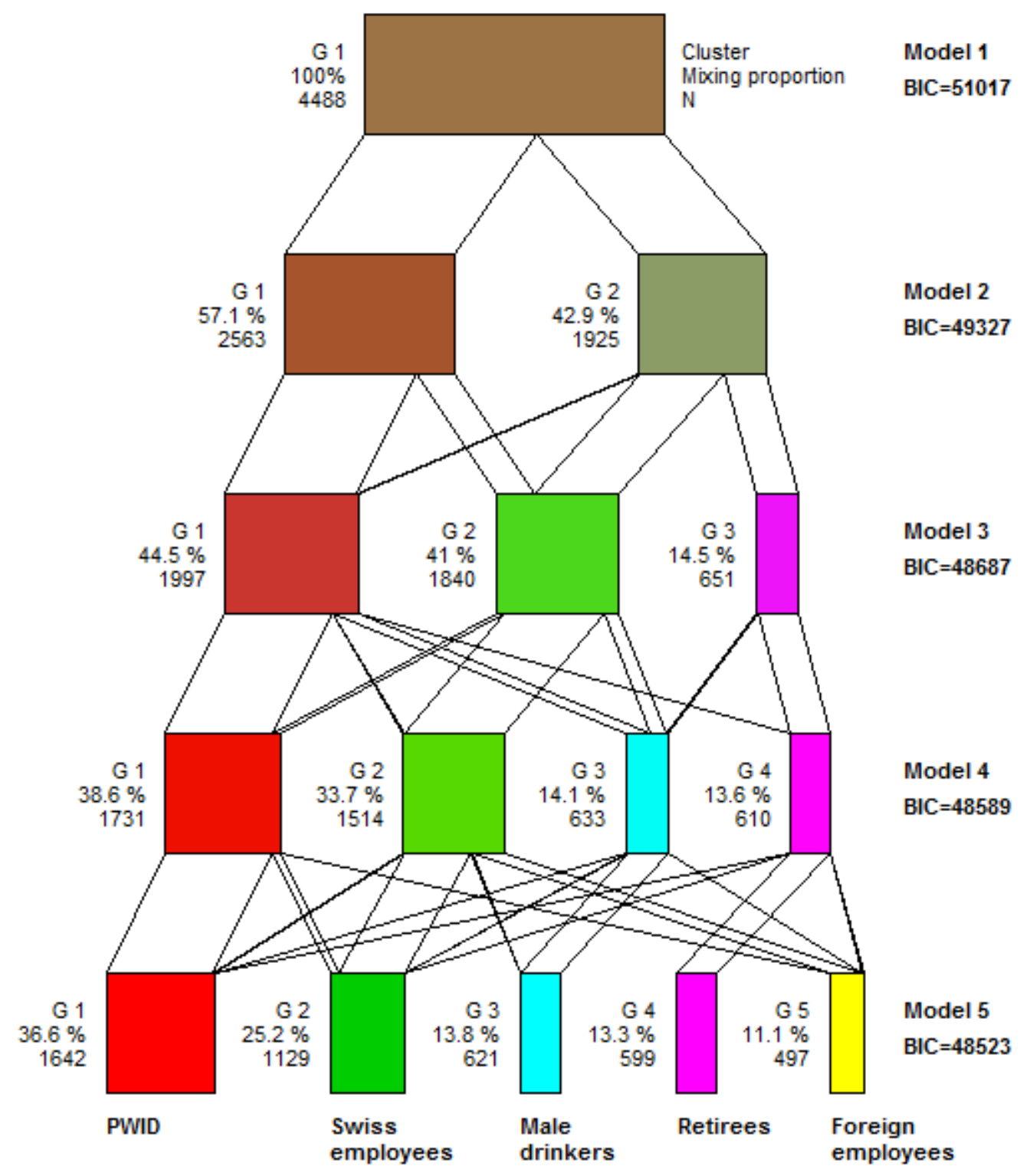

PWID: persons who inject drugs 


\section{Supplementary material}

\section{Table 4: Sensitivity analysis to identify socio-behavioural groups with latent class analysis.}

\begin{tabular}{|c|c|c|c|c|c|c|c|c|c|c|}
\hline & \multicolumn{2}{|c|}{ Swiss employees } & \multicolumn{2}{|c|}{ PWID } & \multicolumn{2}{|c|}{ Male drinkers } & \multicolumn{2}{|c|}{ Foreign employees } & \multicolumn{2}{|c|}{ Retirees } \\
\hline & Model 1 & Model 2 & Model 1 & Model 2 & Model 1 & Model 2 & Model 1 & Model 2 & Model 1 & Model 2 \\
\hline No. of participants (\%) & $1,129(25.2)$ & $1,093(24.3)$ & $1,642(36.6)$ & $1,490(33.2)$ & $621(13.8)$ & $824(18.4)$ & $497(11.1)$ & 488 (10.9) & $599(13.3)$ & $593(13.2)$ \\
\hline $\begin{array}{l}\text { Membership probability } \\
\text { (interquartile range) }\end{array}$ & $\begin{array}{c}0.92 \\
(0.70-0.94)\end{array}$ & $\begin{array}{c}0.89 \\
(0.73-0.93)\end{array}$ & $\begin{array}{c}0.85 \\
(0.66-0.96)\end{array}$ & $\begin{array}{c}0.91 \\
(0.67-0.99)\end{array}$ & $\begin{array}{c}0.61 \\
(0.57-0.64)\end{array}$ & $\begin{array}{c}0.67 \\
(0.56-0.79)\end{array}$ & $\begin{array}{c}0.76 \\
(0.68-0.86)\end{array}$ & $\begin{array}{c}0.72 \\
(0.58-0.80)\end{array}$ & $\begin{array}{c}0.99 \\
(0.94-1.00)\end{array}$ & $\begin{array}{c}0.99 \\
(0.97-1.00)\end{array}$ \\
\hline No. of women & $618(54.7)$ & $515(47.1)$ & $526(32.0)$ & $524(35.2)$ & $6(1.0)$ & $116(14.1)$ & $203(40.8)$ & $195(40.0)$ & 305 (50.9) & 308 (51.9) \\
\hline $\begin{array}{l}\text { Median (interquartile range) age, } \\
\text { years }\end{array}$ & $44(38-50)$ & $45(39-51)$ & $37(32-42)$ & 35 (32-39) & $48(44-52)$ & $47(44-51)$ & $41(35-49)$ & $41(35-49)$ & $64(60-68)$ & $64(60-68)$ \\
\hline Swiss nationality & $1,113(98.6)$ & 1,035 (94.7) & $1,252(76.2)$ & $1,151(77.2)$ & $522(84.1)$ & $698(84.7)$ & $0(0.0)$ & $0(0.0)$ & 405 (67.6) & $408(68.8)$ \\
\hline \multicolumn{11}{|l|}{ Education $^{a}$} \\
\hline lower & $77(6.8)$ & $61(5.6)$ & $603(36.7)$ & $504(33.8)$ & $14(2.2)$ & $141(17.1)$ & $138(27.8)$ & $134(27.5)$ & $134(22.4)$ & $126(21.2)$ \\
\hline medium & $689(61.0)$ & $639(58.5)$ & 1,001 (61.0) & $932(62.5)$ & $450(72.5)$ & $548(66.5)$ & $200(40.2)$ & $219(44.99$ & $334(55.8)$ & $336(56.7)$ \\
\hline higher & $344(30.5)$ & $374(34.2)$ & $20(1.2)$ & $38(2.5)$ & $148(23.8)$ & $125(15.2)$ & $150(30.2)$ & $125(25.6)$ & 119 (19.9) & $119(20.1)$ \\
\hline \multicolumn{11}{|l|}{ Occupational status } \\
\hline worker / student & $1,078(95.5)$ & 1,057 (96.7) & $687(41.8)$ & $648(43.5)$ & $394(63.4)$ & $461(56.0)$ & 447 (89.9) & 440 (90.2) & 131 (21.9) & $131(22.1)$ \\
\hline retired / social assistance & $10(0.9)$ & $0(0.0)$ & $563(34.3)$ & $467(31.3)$ & 192 (30.9) & 304 (36.9) & $9(1.8)$ & $9(1.8)$ & $462(77.1)$ & 456 (76.9) \\
\hline unemployed & $35(3.1)$ & $31(2.8)$ & $385(23.4)$ & $369(24.8)$ & $33(5.3)$ & $55(6.7)$ & $37(7.4)$ & $35(7.7)$ & $3(0.5)$ & $3(0.5)$ \\
\hline \multicolumn{11}{|l|}{ Alcohol consumption ${ }^{b}$} \\
\hline no or light drinker & $979(86.7)$ & $930(85.1)$ & $637(38.8)$ & $662(44.4)$ & $0(0.0)$ & $36(4.4)$ & $375(75.4)$ & $360(73.8)$ & $442(73.8)$ & 445 (75.0) \\
\hline moderate-heavy drinker & $39(3.4)$ & $52(4.8)$ & $331(20.2)$ & $282(18.9)$ & $211(34.0)$ & $241(29.2)$ & $26(5.2)$ & $35(7.2)$ & $56(9.3)$ & $53(8.9)$ \\
\hline former moderate-heavy drinker & $111(9.8)$ & $111(10.2)$ & $674(41.0)$ & $546(36.6)$ & $410(66.0)$ & $547(66.4)$ & $96(19.3)$ & $93(19.1)$ & 101 (16.9) & $95(16.0)$ \\
\hline \multicolumn{11}{|l|}{ Drug use } \\
\hline no & $688(60.9)$ & $712(65.1)$ & $16(1.0)$ & $19(1.3)$ & $190(30.6)$ & $157(19.0)$ & 457 (92.0) & 467 (95.7) & 594 (99.2) & $587(99.0)$ \\
\hline current & & $249(22.8)$ & & 1,355 (90.9) & & $413(50.1)$ & & $0(0.0)$ & & $1(0.2)$ \\
\hline former & $43 /(38.1)$ & $121(11.1)$ & $1,625(99.0)$ & $105(7.1)$ & $429(69.1)$ & $248(30.1)$ & $38(1.6)$ & $19(3.9)$ & $1(0.2)$ & $0(0.0)$ \\
\hline
\end{tabular}

PWID: persons who inject drugs

Model 1: model used for main analysis, with drug use divided into no or yes.

Model 2: model used for sensitivity analysis, with drug use divided into no, current and former.

a Education: defined according to the Swiss Conference of Cantonal Ministers of Education.

${ }^{\mathrm{b}}$ Alcohol consumption: no or light drinker ( $\leq 20 \mathrm{~g}$ alcohol/day), moderate-heavy drinker (>20 g alcohol/day) and former moderate-heavy drinker (used to drink >20 g alcohol/day before, but currently stopped). 


\section{Statement of Interests}

Barbara Bertisch has served as advisor for Janssen and BMS, has received research grants from Gilead and BMS and has obtained honoraria for speaking at a meeting from BMS and Gilead.

Francesco Negro has served as advisor for MSD, Gilead, BMS, and AbbVie and has received unrestricted research grants from Gilead.

Guido Stirnimann has served as an advisory board member for AbbVie.

Beat Müllhaupt has served as an advisory board member for Roche, MSD, Janssen, AbbVie, Boehringer Ingelheim, Gilead and BMS; as consultant for Gilead and AbbVie; and has received research grants from Roche and Gilead.

Darius Moradpour has served as an advisory board member for AbbVie, BMS, Gilead, Janssen, MSD and Roche and has received research and/or travel grants from BMS, Gilead, MSD and Roche.

Andreas Cerny has no conflicts of interest to declare. 